\title{
On Reform Models of Physical Education in Secondary
}

\section{Vocational Schools}

\author{
Xiulan Liu \\ Department of Physical Education, Secondary Vocational School, Dezhou University \\ No. 67, Communist Youth League Road, Dezhou 253000, China \\ E-mail: 1x198881@163.com
}

\begin{abstract}
Today, secondary vocational education tends to display its irreplaceable educational advantages. And physical education is also very important in secondary vocational education. Therefore, how to make lesson planning for physical education and write teaching plans are the top priority, which can help to realize nice teaching effects, improve teaching quality, and also students' integrated quality.
\end{abstract}

Keywords: Secondary vocational education, Physical education, Lesson planning, Teaching plan

1. The secondary vocational education is carried out at the stage of high school, aiming at training hundreds of millions of skilled personnel and high-quality laborers based on nine-year compulsory education.

The secondary vocational education is currently the main body of vocational education in China, which is mainly performed by secondary vocational schools. The enrollment targets at graduates from junior secondary school and people with equivalent educational history. The length of schooling is basically three years. These secondary vocational schools can provide students with knowledge of high school education, and vocational knowledge and technique training according to requirements of vocational positions.

2. Considering the characteristics of students in secondary vocational schools, we should make relevant teaching plans. Most students are still at the stage of body growing. In order to improve their physical fitness, physical education is extremely important.

Today, most people think that physical education is easy since it is nothing more than activities. As a matter of fact, this view is very wrong. Sports have deep historical background, knowledge, and skills. Like other disciplines, physical education teachers must make lesson planning, and write teaching plans. The contents of lesson planning should be detailed, elaborate, and complete. The teaching plans must point out the keys and the difficulties, and choose the teaching methods. Then, it can achieve the purpose of instruction. Then, how teachers make lesson planning and write teaching plans? Next, we will make a detailed discussion.

3. In order to make lesson planning for physical education, we must follow the principles of physical education firstly.

Rules for lesson planning

In physical education, there are some teaching principles we must follow, including: the principle of full development of body and mind, the principle of intuition, the principle of step-by-step, the principle of consolidation and improvement, the principle of starting from reality, the principle of arranging exercises reasonably, the principle of integrated innovation, etc. We should follow these principles of teaching, reasonably arrange teaching contents and choose teaching methods, and make lesson planning carefully.

\subsection{Improve and enhance the level of organization}

PE teachers should organize the teaching precisely, using the proper teaching methods according to the number of students, the traits of teaching materials, and conditions of playgrounds and equipments. Minimize the time for organizing the entire team, mobilizing the team, arranging playgrounds and equipments, grouping, and collecting. For example, we can arrange some exercises to mobilize the team, and train students' ability of moving heavy loads by installing and clearing equipments.

\subsection{Motivate students' enthusiasm for learning}

Only when students prefer to study, can they cooperate teachers' teaching actively, and get the initiative to study. By this way, it realizes the teaching objectives and the real purpose of physical education. 


\subsection{Establish reasonable and correct teaching objectives}

If teaching objectives are too tough to be reached by students through their own efforts, they will feel frustrated and may loose motivation to continue learning. In contrast, if teaching objectives are too simple, and can be achieved without efforts, on one hand, they will feel a little challenge and loose learning interests. On the other hand, they can not get benefits from PE lessons. Therefore, the establishment of teaching objectives must be based on students' real conditions.

To prepare a nice PE class requires the teacher possess solid special knowledge, rich education knowledge, and expansive cultural and scientific base. It means we continue to improve ourselves to adapt to social needs and the development of times. Besides, we should always pay attention to the development of sports, the reform of PE curricula, and the growth of students, what is the guaranty for a good PE class.

\section{How to make lesson planning (from two aspects)}

\subsection{Procedures and methods of lesson planning}

(1) Firstly familiarize and master the syllabus and teaching materials

Once a teacher takes the teaching mission, before the start of the lesson he or she should read through the teaching materials and know about the class thoroughly by referencing to the requirements of syllabus, teaching progress, and distribution of teaching time, probe into the inner connection and the characteristics of teaching materials, thinks over the focus of teaching materials, the exercises, and group exercises carefully, analyze the contents of teaching materials, and make up the lesson's objectives, tasks, teaching requirements, emphases, difficulties, organization forms, exercises, teaching methods, and possible errors, and correcting methods. The more the teacher understands the teaching materials and syllabus, the more precise the teacher identifies the emphases, the easier the teacher makes breakthrough and students understand, catch up, exercise, and master the technique. Meanwhile, the PE teacher should frequently review and check through the sports-related knowledge, master and research all sports' techniques, and exercising methods. Besides, the teacher should accumulate relevant materials at any time, read more sports journals, books, newspapers, watch TV programs, listen to broadcasting, take a part in teaching activities and communication, integrate and store advanced teaching experiences and best training methods, for the sake of convenient use.

(2) Carefully deal with the relation of teacher as the guide and students as the main body

Some PE teachers keep to the traditional teaching idea which focuses on "teaching materials, technique and teaching methods, teachers, and playgrounds", forgetting the principle of taking students as the main body. Actually, a PE teacher should hold the "students-oriented" teaching idea, and plan the contents of class scientifically, reasonably, effectively, and actively, considering students' physical abilities, health, psychological qualities, and morals. Strengthen trainings for students' scientific thinking, sports techniques, and abilities. Cultivate students' self-taught ability, ability of independent work, ability of analyzing and solving problems, ability of self-training, ability of communication, ability of expression, ability of summarizing experiences, and ability of innovation. The teacher must study carefully and make reasonable arrangement in lesson planning. Besides, in lesson planning the teacher must think about how to motivate students' enthusiasm for study, trigger out students' subjective initiative, stimulate the desire for knowledge, select the optimal teaching methods and speed, and identify the interesting and competitive parts from the teaching materials' basic theoretical knowledge, and scientific and practical sports techniques. Use vivid ways to illustrate the relationship between sports, strong body, and social development. Help students to build correct view of sports. Instruct students in independent thinking and scientific exercising. And the teacher should help students to update the knowledge and the technique continuously. Train students to acquire the ability of innovation and make best use of knowledge and technique learned in class.

As far as students are concerned, the teacher should know about the objects of teaching: how many students in the class, the number of female, the number of male, and even the physical and psychological conditions of everybody. Only by knowing about the students, can we give the proper instruction for each student.

(3) Know about the teaching environment

Teaching environment is the integration of all exterior conditions that affect people's physical and psychological development spontaneously. Its connotation includes the social environment and atmosphere, such as trans-school or class communication, interpersonal relationship, study atmosphere, spare life, and teaching management. These factors intertwine and form a relatively stable fashion. They are also potential teaching and educational elements. Somebody names teaching and educational element as "potential course". The teaching environment and PE teaching effect are closely connected but mutually restricted. A positive teaching 
environment is the precondition for achieving the best teaching effect. Therefore, in lesson planning the teacher should never ignore the influences of teaching environment. The designed contents and plans should help to deepen and enlarge the knowledge, to stimulate students' initiative and enthusiasm for learning, and to promote students' multi-ability development. So, in designing lessons, the teacher should carefully choose and use the teaching environment, and maintain a "dynamic balance" with environment. By this way, the teacher can perform a nice lesson planning and make best use of the lesson.

As far as playground and equipments are concerned, the teacher should choose the right playground and prepare teaching equipments in advance, according to the teaching contents and the conditions of students. Here, the teacher should consider some unexpected condition. For example, if there is no proper equipment or insufficient equipment, how the teacher change and organize the lesson.

(4) Know about the changes of weather

The PE teacher should always keep an eye on the change of weather, because he or she has to change the teaching contents according to the weather.

(5) Group lesson planning and pools ones wisdom

As planning lessons, the teacher should advocate the policy of "diversity" and perform the collective lesson planning. In aspects of teaching contents, methods, playgrounds, and equipments, it should be allowed to present different ideas, encouraging innovations and experiments. If an agreement can not be reached temporarily, all teachers should make teaching plans based on special discussion. In addition, the PE teachers must join in physical training in order to maintain and improve the ability of techniques. It can help to build a correct image of sports. For group lesson planning, all PE teachers should join in a class show because it is an important content for a successful lesson.

In a word, a teacher must plan lesson carefully in order to give a successful lesson. The goal of lesson planning is to write high-quality teaching plans, which can not only improve the teaching effects, but also gradually enhance teachers' ability of mastering teaching materials, understanding students, and designing lessons, achieving the mutual positive influences between teachers and students. Considering the goal of lesson planning, it is necessary to discuss how to write teaching plans.

\section{Teaching plans for PE class are fruits of lesson planning}

Teaching plans for PE class include two types. The first is theoretical teaching plan, and the other practical teaching plans.

\subsection{How to write the theoretical teaching plans for PE class}

(1) Establish the objectives of teaching. For theoretical lessons, the objectives of teaching usually concern two aspects: knowledge and techniques, and morals. To establish and confirm the objectives, teachers should consider the characteristics of teaching contents and materials, the real conditions of students. And the objectives should be overall, clear, specific, and practical.

(2) Grasp the emphases and difficulties in teaching. The theoretical teaching is usually around one teaching material. So, the emphases of the lesson are the same as that of the teaching material. The emphases in teaching are the parts that must be pointed out in teaching, what are the key for achieving the objectives of teaching. Generally speaking, the knowledge and abilities established in objectives of teaching are the emphases of teaching for the lesson. What are hard for students to understand and master are difficulties of teaching. For the emphases and difficulties in teaching, teachers should make careful lesson planning and explain to students clearly.

(3) Design teaching process and choose teaching method. Teaching process is the procedure, which deserves a precise design. The teacher should consider a series of issues in advance: what first, what next, how to explain, how to ask questions, how distribute the time, etc. The choice of teaching method is based on objectives of teaching, characteristics of teaching materials, and conditions of students.

(4) Design the board writing. The board writing is the highly-summarized class teaching, which reflects the intentions of teachers' teaching. Therefore, it deserves a careful thought and a delicate design. The board writing should be neat and highly summarized, with prominent emphases and reasonable arrangement. The useful board writing can strengthen effects of teaching, deepen students' impression, and improve learning effects.

\subsection{How to write the practical teaching plans for PE class}

(1) Study the course standards and teaching materials and establish objectives of teaching. Based on studying the 
course standards and teaching materials, the teacher can master the fundamental ideas of teaching materials, and understand the requirements for students in learning the concepts and theories. Establish the objectives of teaching in one class.

(2) Confirm the position of one class in the whole teaching material, and establish the emphases and difficulties. Based on researching the whole teaching material, the teacher can confirm the position of one class and the emphases and difficulties. The so-called emphases are key knowledge. Once students understand the emphases, others become easier. The so-called difficulties are relative. Students usually misunderstand or fail to understand the difficulties. Actually, students at different levels have different difficulties.

(3) Organize teaching materials and choose teaching method.

According to principles of teaching and characteristics of teaching materials, the teacher can organize teaching materials and choose teaching method based on conditions of students, playgrounds, and equipments, designing the whole teaching process. The organization of teaching materials is various. The same teaching material may form different organizational structure. However, no matter what the structure is, it must be around the contents. The teacher can determine the teaching process by understanding the inner connection of teaching material.

(4) Design teaching procedures and arrange the time. In writing the teaching plans, the teacher should think about a series of issues: how to introduce new project by reviewing old knowledge, how to develop the new knowledge, how to emphasize the key, how to explain the difficulties, how to solve problems in exercises, how to consolidate the knowledge and techniques, and how to distribute the time, etc.

Judging from the relationship between lesson planning and teaching plans, the lesson planning is a special process, in which the teacher studies and communicates with the teaching material independently, acquires unique experiences and feelings, designs the teaching process creatively, chooses and optimizes teaching tactics and methods according to conditions of students. Teaching plans display the fruits of lesson planning, especially the creative parts but not contents of teaching material. What the teacher will tell students are in the mind but not in written. In a sense, teaching plans are the reflection of lesson planning. Lesson planning is the base for teaching plans. The two are closely intertwined. But we can not equalize teaching plans with lesson planning.

To sum up, the lesson planning for PE class in secondary vocational schools is very important. If a teacher can follow these points above, a successful PE class will be easier and can achieve better teaching effects.

\section{References}

Chen, Chuanzhong. (2001). Six key elements for PE lesson planning. Journal of Huazhong Normal University, No. 3 .

Liu, Lian. (2010). On cooperative lesson planning for PE. Science and Technology Information, No. 1.

Ren, Jingyan. (1997). College PE. Nanjing: Jiangsu People's Publishing House, Mar.

Teaching materials composing group for school physical education. (1995). School Physical Education. Beijing: People's Physical Education Press.

Xiang, Lianghong. (2009). The research on practices of group lesson planning for PE. Sports News, Aug.

Yin, Zhidong. (2009). College Physical Education and Health. Dalian: Dalian University of Technology Press, July.

$\mathrm{Zu}$, Ying. (2006). Discussion on the importance of preparing lessons of improving the quality of PE teaching in colleges and universities. Journal of Harbin Physical Education Institute, No. 4. 